\title{
Measuring customer satisfaction with some of the controllable elements of the total retail experience: An exploratory study
}

\author{
N.S. Terblanche* \\ Department of Business Management, University of Stellenbosch 7600, \\ Republic of South Africa \\ nst@maties.sun.ac.za \\ C. Boshoff \\ Department of Business Management, University of Port Elizabeth, PO Box 1600 \\ Port Elizabeth 6000, Republic of South Africa \\ Received July 2001
}

\begin{abstract}
Total retail experience is, for the purposes of this study, defined as all the elements that encourage or inhibit consumers during their contact with a retailer. This article reports on the influence of three dimensions of consumers' total retail experience on their satisfaction levels. The items used to measure the theoretical model demonstrate sufficient reliability and discriminant validity. The theoretical model is then tested using a structural equation modeling approach. Although not a test of a comprehensive model of the total retail experience, the study does shows that the personal interaction between retail employee and customer on the one hand, and physical cues on the other hand, impact strongly on customer satisfaction.
\end{abstract}

*To whom all correspondence should be addressed.

\section{Introduction}

The retail environment is constantly adjusting to accommodate changes in the environment. Competition and consumers are two important environmental forces driving the volatility in the retail sector. Competition presents itself in the form of new entrants and formats as well as foreign competition. Today's consumers are also more demanding than before. Not only do they have more choices than ever before; they also have more information at their disposal than ever before. In order to differentiate itself and attract and retain customers, a retailer has to differentiate itself and its brands. Many retailers have implemented loyalty schemes for this purpose.

Other retailers use service quality as a means of differentiating themselves in an increasingly competitive environment (Berry, 1986; Hummel \& Savitt, 1988; Reichheld \& Sasser, 1990). The marketing literature of the past decade devoted many pages to service quality, especially to SERVQUAL, the instrument developed to measure service quality (Parasuraman, Zeithaml \& Berry, 1988). The majority of the studies using or assessing the SERVQUAL instrument were executed in fairly 'pure' services settings such as banking, credit card services and securities brokerage. A retail store experience involves activities such as browsing, price comparisons, search for merchandise, evaluating product variety and quality and interaction with store personnel. The SERVQUAL instrument in its original form is therefore not suitable to capture the unique blend of merchandise and service that constitutes a retailing experience. Dabholkar, Thorpe and
Rentz (1996) recently proposed an instrument based on SERVQUAL, which they suggest, measures service quality in a retailing environment. This instrument also captures, apart from the common dimensions that are likely to be shared by pure service environments and retail environments, additional dimensions of retail service quality unique to the retail environment. The development of the instrument is justified on the grounds that current measures of service quality do not adequately capture customers' perceptions of service quality for retail stores (i.e. stores that offer a mix of goods and services). Although the Dabholkar, Thorpe and Rentz (1996) study contributed to a greater understanding of service quality in certain retail stores, it was criticised, amongst other things, because it failed to investigate the relationship between customer perceptions of the quality of the products a retailer carries and customer perceptions of the service quality provided by the retailer (Finn \& Kayandé, 1997:2). Finn and Lamb (1991) also found limitations in respect of the application of SERVQUAL in certain retail settings. They tested SERVQUAL in four different types of retail stores and were unable to find a good fit to the five-factor structure. They concluded that SERVQUAL, without modification, could not be used as a valid measure of service quality in a retail setting.

A third alternative available to retailers with which they can differentiate themselves, is to provide a positive total retail experience (TRE) for their clients. Berman and Evans (1998:19) define total retail experience as all the elements that encourage or inhibit consumers during their contact with the retailer. In this perspective service quality is only 
one component of the consumer's total retailing experience. From a measurement and management perspective, it also seems preferable to develop an instrument that captures all the dimensions of a shopping experience that can be controlled by a retailer. Our contention is that in a retail environment where a mix of goods and services is offered, the approach should preferably be all-inclusive and the focus should rather be on the management of the controllable elements of the total retail experience as opposed to a perspective restricted to the management of say, service quality only. If only one component of the total retailing experience is considered at a time, it might be detrimental to our understanding of customers' in-store experiences and this in turn could lead to strategies that either overemphasize or under appreciate the importance of one or more of such components.

\section{Purpose}

This article reports on the first phase of a long-term study on the controllable elements of the total retail experience. It is therefore necessary to distinguish between the long-term and short-term objectives of the study. The eventual outcome of
The literature study, which led to the model of the controllable elements of the TRE in Figure 1, suggested that TRE consists of six components or dimensions. The focus groups, which preceded the survey phase of this exploratory study, suggested that three of these six dimensions are particularly important to consumers. Also, the literature review (supported by the focus groups) suggested that these three dimensions might consist of sub-dimensions. Due to the extent of these variables and concern about respondent fatigue only three variables (service quality, product quality and product variety and assortment) were empirically tested in this first phase of the study.

\section{Objectives}

The objective of this study, as part of the first phase of research, was to assess the influence of three dimensions (namely service quality, product quality, and product variety/assortment) of the TRE on customers' level of satisfaction. In this study the dimensions of service quality, product quality, and product variety/assortment were modelled as exogenous latent variables and satisfaction was modelled as an endogenous latent variable.

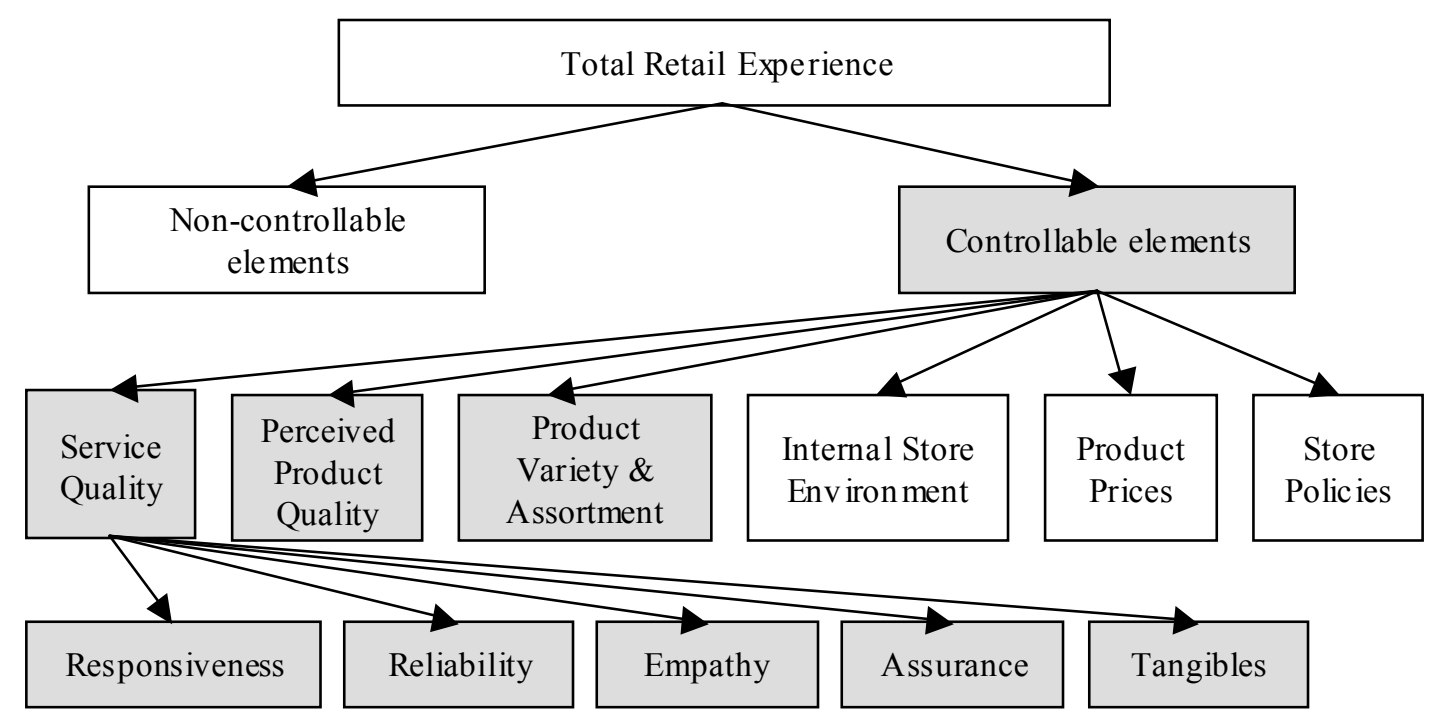

Figure 1 schematic presentation of the theoretical structure of the total retail experience*

*The shaded areas represent the dimensions studied in this first phase of the research.

this stream of research, of which this exploratory study is only an initial phase, is to develop an instrument to measure the satisfaction with selected components of the total retail experience. Only once these dimensions have been identified empirically, can we proceed to the development of a valid and reliable instrument to measure consumer satisfaction with the total retail experience at retailer or shop level. Two follow-up surveys are envisaged for such purposes.

\section{Components of the total retail experience}

As illustrated in Figure 1, the total retail experience is influenced by two groups of components. The first group consists of the non-controllable components. The noncontrollable components include aspects such as adequacy of street parking, timing of deliveries from suppliers and taxes, all of which are not controllable by the retailer. The controllable components, in turn, consist of a variety of elements that the retailer can control, such as the number of salespeople on the floor, variety of brands carried and stock on hand. The retail literature suggests that the dimensions of 
the controllable components may be grouped under six dimensions. These six dimensions may be described as:

- Service quality

- Perceived product quality

- Product variety and assortment

- Internal store environment

- $\quad$ Product prices

- Store policies

In this study the focus is on three of the controllable elements of the total retail experience. Only limited possible dimensions of TRE were researched initially due to the large number of items tested and concern about respondent fatigue as respondents were interviewed personally with the aid of a structured questionnaire.

\section{Service quality as a dimension of the total retail experience}

Despite the criticism levelled against SERVQUAL (Buttle, 1995), the scale designed to measure the five dimensions of service quality, the items used for the measurement of the various dimensions of service quality were regarded as suitable to measure some of the controllable elements of the TRE. It is also, however, known that SERVQUAL in its original form is not suitable to capture the unique blend of merchandise and service that makes a retailing experience. Also, the fact that various studies that analysed and used SERVQUAL have reported empirical factor structures which differed from the five factor structure reported by Parasuraman, Zeithaml and Berry (1988:199). The intention of this study was, amongst others, to establish which dimensions of SERVQUAL will remain when subjected to analysis in a retail environment with a blend of merchandise and service. With the above in mind all 22 items of the SERVQUAL scale were used in this study.

\section{Perceived product quality as a dimension of the total retail experience}

Several researchers have identified perceived product quality as a causal determinant of a consumer's perceived value of a product (Dodds, Monroe \& Grewal, 1991; Kerin, Jain \& Howard, 1992:382). Perceived product quality could therefore be expected to have an influence on the TRE of a consumer. Various researchers have also reported on the importance of the quality of products (merchandise) in consumers' perception and evaluation of retail shops (Dabholkar, Thorpe \& Rentz, 1994:4). In a more recent study Sirohi, Mclaughlin and Wittink (1998:240) operationalised product quality for a supermarket with fifteen indicators. These indicators included quality items related to the grocery, bakery, frozen food, meat, health and beauty and other departments of a supermarket. Some retailers position themselves mainly on the basis of the quality level of the product. Retailers selling high quality, high priced, well-known luxury brands are examples in this respect.

Product variety and assortment as a dimension of the total retail experience
Product variety and assortment are components of the conventional retail marketing mix (Hasty \& Reardon, 1997:11). Products are probably the most complex expectation customers have of retail shops because customers expect to find a variety or a selection of different kinds of products that are consistent with personal shopping intention and preferences (Davidson, Sweeney \& Stampfl, 1988:141). The range of food and non-food product lines that supermarkets, for instance, offer, illustrates the complexity of the product variety decision. The opposite of this is the 'super-specialisation' of speciality retailers. Assortment is closely related to variety, as it is the range of choice offered within a category of products. Consumers therefore not only expect to find a variety of products, but also an assortment of different colours, brands, styles, models and sizes for each product line. Product variety and the depth of assortment will to a large extent be influenced by the image the retailer wishes to project. For instance, a supermarket's product variety and assortment is associated with the customer services and facilities of the supermarket (Bishop, 1984; Doyle, 1984). Kerin, Jain and Howard (1992:385) also reported that previous research and focus groups found overall variety and assortment to be indicators of shopping experience. In a study of men's clothing, overall assortment featured as a strong determinant of shop patronage (King \& Ring, 1980:50). The importance of assortment and variety in retailing is also confirmed by the fact that one of the items of the Index of Consumer Sentiment Toward Marketing deals with the adequacy of the selection of products offered by retail shops (Gaski \& Etzel, 1986:79). Unlimited selection of products has also been identified as one of the 13 items that contribute to a reliable store image for discount and department stores $(\mathrm{Wu} \&$ Petroshuis, 1987:47).

\section{Internal store environment, product prices and store policies as dimensions of the total retail experience}

The other three dimensions of TRE that are not dealt with in this article are internal store environment, product prices and store policies. For the sake of contextualisation, each of these dimensions will be briefly discussed here.

Internal store environment includes all those elements that contribute towards a pleasant shopping atmosphere. These elements are shop layout, aisles that make it easy to shop, store cleanliness, well-spaced product displays and attractive décor. The retail literature suggests that customers value the convenience that physical aspects, such as store layout, contribute to shopping (Gutman \& Alden, 1985; Hummel \& Savitt, 1988; Mazursky \& Jacoby, 1985; Oliver, 1981).

Gaski and Etzel (1986) used price as a category in their Index of Consumer Sentiment Toward Marketing. This indicates the importance of prices in consumer decisionmaking. In the absence of other cues, consumers tend to use price as an indicator of product quality (Davidson, Sweeney \& Stampfl, 1988:143).

Store policy as a dimension of the total retail experience captures those elements that are influenced by a shop's 
responsiveness to the customer's needs (Dabholkar et al., 1996:7). Typical policy elements would be applicable to areas of shop operations such as the return or exchange of purchases, shopping hours, payment options available and a system or process to deal with customer enquiries and/or complaints (Westbrook, 1981; Mazursky \& Jacoby, 1985; Dickson \& Maclachlin, 1990; Dickson \& Albaum, 1977).

\section{Generation of the questionnaire items}

All 22 items of SERVQUAL were used in this study. As stated earlier, various studies reported factor structures which differed from the five-factor structure by Parasuraman, Zeithaml and Berry (1988:199). The intention of the first analysis was therefore also to establish which dimensions of SERVQUAL will remain when subjected to empirical analysis in a retail environment. In other words, the question to be answered was: which dimensions and items of the SERVQUAL scale could be useful to identify and measure some of the dimensions of TRE?

The product variety/assortment and product quality dimensions were measured with self-generated items and published scales. The three product quality items suggested by Finn and Kayandé (1997) were supplemented with two self-generated items. Product variety and assortment were measured with a five-item instrument. The tangible components involved in service delivery were measured with the original four items of SERVQUAL. All items were linked to a 7-point Likert-type scale.

Satisfaction was measured with the following four items:

- Will you continue to buy from XXX in the future?

- How do you rate the overall service of XXX?

- How often have you complained about service in XXX?

- How often have you returned unsatisfactory products to XXX?

\section{Sample and data collection}

The sampling procedure used in this study was a combination of judgement, convenience and random sampling. Four retail industries were selected on a judgmental basis, namely fast food, clothing, supermarkets, and hardware stores. These industries were selected because they offer a combination of both service and physical products and their market offer can neither be described as a 'pure' service nor independent of any service component. Two organisations in each industry were then selected on a convenience basis and requested to participate in the study. All eight organisations operate countrywide and the customers of the individual shops are representative of the organisations' typical customer base. Individual respondents (customers) to be interviewed were selected on a simple random basis. Personal interviews, using a structured questionnaire, were conducted with customers of firms in these four industries on the retailer's premises following a shopping visit. Every fourth customer leaving a shop was approached to take part in the survey. The interviews were conducted over a period of a month to include all the different types of clients in terms of time frequenting the retailers as well as cash and account customers. For instance, it was necessary to conduct interviews at nighttime with clients from the fast food retailers. A total of 2063 questionnaires were completed.

\section{Scale purification}

The first step in the data analysis process was to assess how many dimensions the data contained. For this purpose, a Maximum Likelihood Exploratory Factor Analysis was conducted specifying a Direct Quartimin oblique rotation (Jennrich \& Sampson, 1966) of the original factor matrix. Several different factor solutions were considered. The most interpretable factor structure (factor loading exceeding 0,4 and no crossloadings) to emerge, was a 3 -factor solution. All the factors in the 3 -factor solution had Eigen values above 1,00 and a sufficient number of items loading on them to a significant $(0,40)$ extent (Hair, Anderson, Tatham \& Black, 1998). Table 1 contains the sorted rotated factor loadings matrix. The three factors that emerged were named personal interaction (measured by 3 assurance, 4 empathy, 2 reliability and 3 responsiveness items of SERVQUAL), physical cues (measured by 1 reliability and 2 tangibles items of SERVQUAL and 4 quality items) and variety (represented by 5 variety items). The factor solution in Table 1 shows that the items measuring the tangibles dimension of SERVQUAL and product quality were interpreted as the same construct by respondents and the new dimension is now called physical cues. The items that did not load to a significant extent on a separate factor were excluded from subsequent statistical analyses. The remaining 24 items were then subjected to a reliability analysis to assess the internal consistency of the instrument. All three factors, as well as the overall instrument returned Cronbach alpha coefficients above the 0,7 level suggested by Peterson (1994). The reliability results are summarised in Table 2.

The proposed instrument to measure consumer perceptions of three of the controllable elements of the total retail experience (personal interaction, physical cues and product variety and assortment in Table 3 ) was then subjected to a confirmatory factor analysis to test the measurement model recommended by Gerbing and Anderson (1988). The results of the confirmatory factor analysis are set out in Table 4. The RMSEA of 0,062 suggests that the data fits the theoretical model in Figure 2 reasonably well (Steiger \& Lind, 1990). The other absolute fit measures reported in Table 4 also meet or exceed the minimum levels normally regarded as cut-off points. Both the LISREL Goodness of Fit Index and the Adjusted Goodness of Fit Index exceed the customary cut-off point of 0,900 , providing additional support for the conclusion that the data fits the theoretical model reasonably well.

\section{Empirical results}

The empirical results reported in Fig 2 show that two of the three dimensions of the total retail experience that emerged from the exploratory factor analysis impact on customer satisfaction. Personal interaction is the strongest predictor of customer satisfaction $(0,585 ; \mathrm{p}<0.01)$ followed by physical 
cues $(0,312 ; p<0.01)$. For this sample, variety of merchandise does not influence customer satisfaction. All the inter-correlations among the three exogenous latent variables are significant $(\mathrm{p}<0.01)$.

Table 1: Sorted rotated factor loadings

\begin{tabular}{|c|c|c|c|}
\hline & $\begin{array}{c}\text { Factor } 1 \\
\text { Personal } \\
\text { interaction }\end{array}$ & $\begin{array}{c}\text { Factor } 2 \\
\text { Physical } \\
\text { cues }\end{array}$ & $\begin{array}{c}\text { Factor } 3 \\
\text { Product } \\
\text { variety and } \\
\text { assortment }\end{array}$ \\
\hline PERS 1 & 0,859 & $-0,024$ & $-0,047$ \\
\hline PERS 2 & 0,826 & $-0,080$ & 0,022 \\
\hline PERS 3 & 0,798 & $-0,022$ & $-0,032$ \\
\hline PERS 4 & 0,758 & 0,050 & $-0,067$ \\
\hline PERS 5 & 0,751 & $-0,048$ & 0,038 \\
\hline PERS 6 & 0,740 & $-0,006$ & 0,041 \\
\hline PERS 7 & 0,731 & 0,035 & $-0,016$ \\
\hline PERS 8 & 0,662 & 0,117 & $-0,044$ \\
\hline PERS 9 & 0,626 & $-0,024$ & 0,227 \\
\hline PERS 10 & 0,614 & 0,110 & 0,080 \\
\hline PERS 11 & 0,578 & 0,082 & 0,170 \\
\hline PERS 12 & 0,458 & 0,281 & 0,013 \\
\hline PHYS 1 & $-0,087$ & 0,826 & 0,035 \\
\hline PHYS 2 & $-0,058$ & 0,810 & 0,090 \\
\hline PHYS 3 & 0,024 & 0,770 & 0,039 \\
\hline PHYS 4 & 0,157 & $\mathbf{0 , 5 3 9}$ & $-0,014$ \\
\hline PHYS 5 & 0,075 & 0,448 & 0,155 \\
\hline PHYS 6 & 0,272 & 0,444 & $-0,042$ \\
\hline PHYS 7 & 0,148 & 0,400 & 0,117 \\
\hline VARI 1 & $-0,007$ & 0,086 & 0,805 \\
\hline VARI 2 & 0,042 & $-0,113$ & 0,793 \\
\hline VARI 3 & $-0,046$ & 0,099 & 0,660 \\
\hline VARI 4 & 0,038 & 0,118 & 0,659 \\
\hline VARI 5 & 0,146 & 0,166 & 0,434 \\
\hline EIGEN & 6,196 & 2,940 & 2,486 \\
\hline
\end{tabular}

Table 2: Reliability analysis results

\begin{tabular}{lc}
\hline \multicolumn{1}{c}{ Dimensions } & $\propto$ \\
\hline Personal interaction &, 937 \\
Physical cues &, 863 \\
Variety &, 857 \\
Customer satisfaction &, 725 \\
Overall &, 948 \\
\hline
\end{tabular}

\section{THE MANAGERIAL IMPLICATIONS}

Many researchers and authors argue that the 'pure' services or a 'pure' physical goods environment does not exist. Instead, consumers buy, they argue, a bundle of benefits that consist of both physical components and service components. The empirical results reported in Figure 2 show that in what was regarded as a 'retail environment' the service component (personal interaction) emerged as the most important predictor of customer satisfaction. This finding also supports the school of thought that argues that physical goods seldom represent a sustainable competitive advantage. Service delivery and particularly personal interaction between employees and customers, they argue, is the only sustainable competitive advantage. Product features and characteristics are easily copied by competitors. Excellent service, on the other hand, calls for top class employees, commitment, effective training, a reward system that recognises good service, a culture of service excellence and a host of other managerial variables that are not easily established, nor easily copied by competitors.

Table 3: Items to measure consumer perceptions of the controllable elements of the total retail experience

\begin{tabular}{ll}
\hline PERSONAL INTERACTION & \\
\hline PERS 1 & Employees of XYZ are always willing to help me \\
PERS 2 & XYZ employees gives me personal attention \\
PERS 3 & Employees of XYZ provide me with prompt service \\
PERS 4 & Employees of XYZ are consistently courteous \\
PERS 5 & XYZ gives me individual attention \\
PERS 6 & Employees of XYZ are never to busy to respond to my requests \\
PERS 7 & When I have a problem, XYZ shows a sincere interest in solving it \\
PERS 8 & I have confidence in XYZ's employees \\
PERS 9 & Employees of XYZ understand my specific needs \\
PERS 10 & Employees of XYZ have the knowledge to answer my questions \\
PERS 11 & XYZ has my best interests at heart \\
PERS 12 & XYZ provides its services at the time it promises to do so \\
& \\
\hline PHYSICAL CUES & \\
\hline PHYS 1 & The products available at XYZ are of good quality \\
PHYS 2 & XYZ's products offer good quality \\
PHYS 3 & XYZ is known for good quality products \\
PHYS 4 & Materials associated with XYZ's service (such as shopping bags, till slips or catalogues) look \\
& good \\
PHYS 5 & XYZ's products seldom have defects \\
PHYS 6 & XYZ's physical facilities look good \\
PHYS 7 & XYZ provides error-free sales transaction records (till slips, credit card slips, accounts) \\
\hline PRODUCT VARIETY AND ASSORTMENT & \\
\hline VARI 1 & XYZ offers me a satisfactory choice of products \\
VARI 2 & XYZ has all the products that I want to buy at a AAA shop \\
VARI 3 & XYZ offers a wide variety of products \\
VARI 4 & The products of XYZ cater for a wide range of preferences \\
&
\end{tabular}


Table 4: Measures of fit of the empirical model

\begin{tabular}{lc}
\hline RMSEA & 0,062 \\
CHI SQUARE & 3105,9 \\
LISREL GFI & 0,900 \\
LISREL ADJUSTED GFI & 0,880 \\
RMR & 0,050 \\
\hline
\end{tabular}

The empirical results obtained in this first phase of research suggest that a retailer that wishes to enhance the total retailing experience of its customers will have to focus its efforts primarily on the interaction between its frontline employees and customers. Employees who are always willing to help, who provide personal, individualised attention, who are courteous when dealing with customers no matter how 'difficult' or demanding they may seem to be, who respond promptly to requests will strongly improve customer satisfaction. In this way retail firms will not only be able to differentiate themselves but also enhance customer satisfaction which should increase customer retention and loyalty.
A second area of focus should be the physical cues that customers encounter when they enter a retail environment. Customer perceptions of the quality of merchandise, the physical store environment (floor covering, lighting, and shelves) and even the appearance of supporting physical equipment such as shopping bags and catalogues, exert a significant influence on customer satisfaction.

In this study variety of merchandise did not emerge as a variable that directly influences customer satisfaction. This conclusion, however, applies to this particular sample. Retailers who wish to measure their customers' satisfaction with their TRE, should include merchandise variety and assortment as a demension, because a different sample might have different perceptions in respect of merchandise variety and assortment. It is also important to note that perceptions of variety and assortment are correlated with both the personal interaction dimension and the physical cues dimension. In other words, by enhancing perceptions of variety and assortment a retailer can indirectly enhance customer satisfaction.

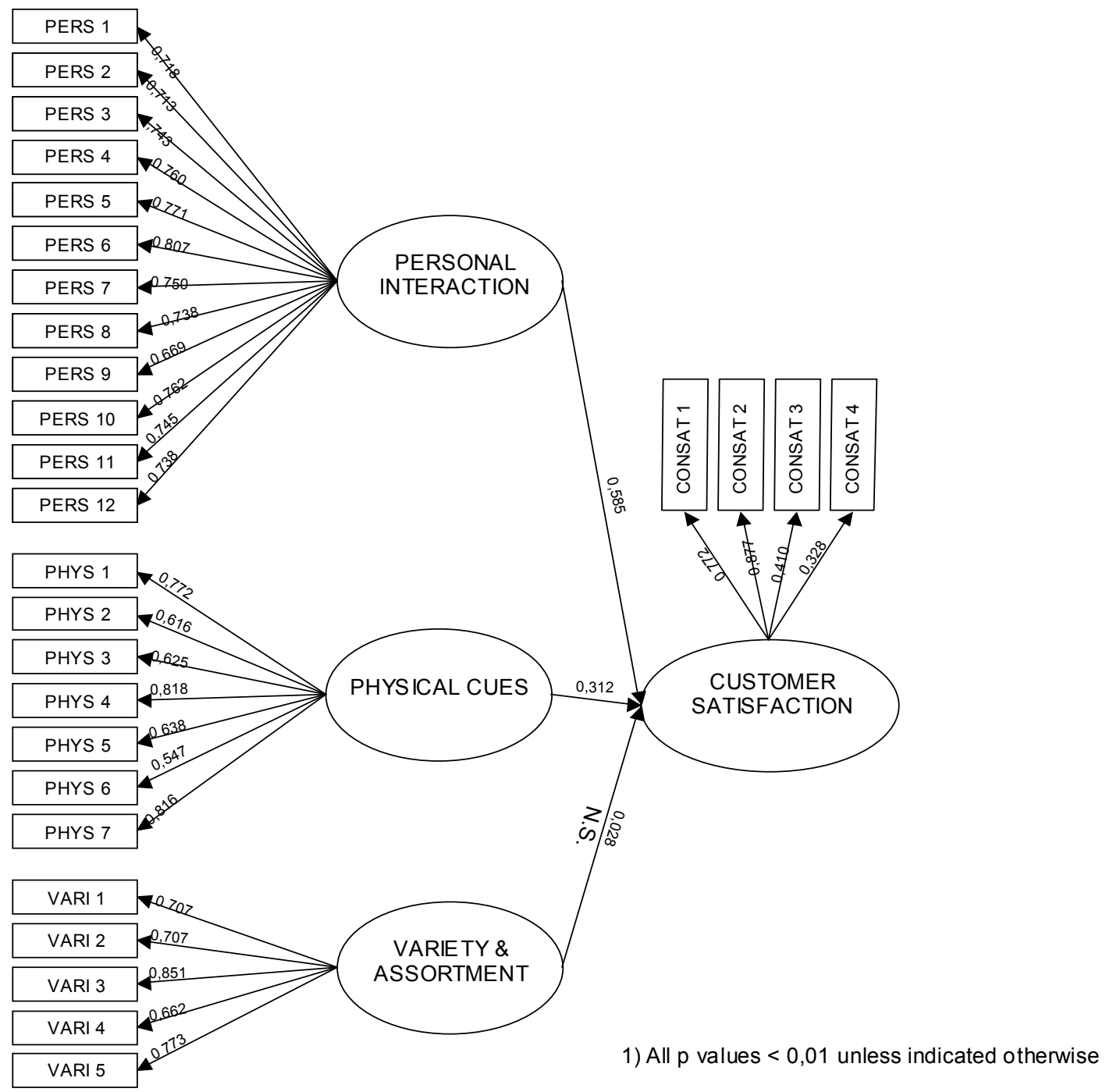

Figure 2: Empirical results: Determinants of satisfaction with selected controllable elements of the total retail experience 


\section{References}

Berman, B. \& Evans, J. R. 1998. Retail management. 7th Edition. Upper Saddle River: Prentice Hall.

Berry, L. L. 1986. 'Retail businesses are service businesses', Journal of Retailing, 62 (Spring):3-6.

Bishop, W.R. 1984. 'Competitive intelligence', Progressive Grocer, March:19-20.

Buttle, F.A. 1995. 'What future for SERVQUAL?', Proceedings of the $24^{\text {th }}$ EMAC Conference, ESSEC, Paris, pp. 211-230.

Dabholkar, P.A., Thorpe, D.I. \& Rentz, J.O. 1996. 'A measure of service quality for retail stores: Scale development and validation', Journal of the Academy of Marketing Science, 24(1):3-16.

Davidson, W.R., Sweeney, D.J. \& Stampfl, R.W. 1988. Retail management. 6th Edition. New York: John Wiley \& Sons.

Dickson, J. \& Albaum, G. 1997. 'A method for developing tailormade semontic differentials for specific marketing content areas', Journal of Marketing Research, 14 (February): 87-91.

Dickson, J.P. \& MacLachlin, D.L. 1990. 'Social distance and shopping behaviour', Journal of the Academy of Marketing Science, 18(2):153-161.

Dodds, W.B., Monroe, K.B. \& Grewal, D. 1991. 'Effects of price, brand, and store information on buyers' product evaluations', Journal of Marketing Research, XXVIII (August): 307-319.

Doyle, M. 1984. 'New ways of measuring value', Progressive Grocer Value, Executive Report, pp.15-19.

Finn, A. \& Kayandé, U. 1997. Consistency of the relationship between retailer product and service quality. Paper read at the $4^{\text {th }}$ Recent Advances in Retailing and Services Science Conference, Scottsdale, Arizona.

Finn, D. W. \& Lamb, C. W. 1991. An evaluation of the SERVQUAL scales in a retail setting. In Holman, R. \& Solomon, M.R. (Eds.). Advances in consumer research. Provo, UT: Association for Consumer Research.

Gaski, J.F. \& Etzel, M.J. 1986. 'The index of consumer sentiment toward marketing', Journal of Marketing, 50 (July):71-81.

Gerbing, D.W. \& Anderson, J.C. 1988. 'An updated paradigm for scale development incorporating unidimensionality and its assessment', Journal of Marketing Research, 25:186-192.

Gutman, J. \& Alden, S.D. 1985. Adolescents' cognitive structures of retail stores and fashion consumption : A means-end chain analysis of quality. In Jacoby, J. \&
Olsen, J. (Eds.). Perceived quality: How consumers view stores and merchandise. Lexington, M.A. : Lexington Books.

Hair, J. F. (Jr.). Anderson, R.E., Tatham, R. L. \& Black, W. C. 1998. Multivariate data analysis. 5th Edition. Upper Saddle River: Prentice Hall.

Hasty, R. \& Reardon, J. 1997. Retail management. New York: McGraw-Hill.

Hummel, J.W. \& Savitt, R. 1988. 'Integrated customer service and retail strategy', International Journal of Retailing, 3(2):5-21.

Jennrich, R.I. \& Sampson, P.F. 1966. 'Rotation for simple loadings', Psychometrika, 31:313-323.

Kerin, R.A., Jain, A. \& Howard, D.J. 1992. 'Store shopping experience and consumer price-quality-value perceptions', Journal of Retailing, 68(4):376-397.

King, C.W. \& Ring, L.J. 1980. 'Market positioning across retail fashion institutions: A comparative analysis of store types', Journal of Retailing, 56(1):37-55.

Mazursky, D. \& Jacoby, J. 1985. Forming impressions of merchandise and service quality. In Jacoby, J. \& Olsen, J. (Eds.). Perceived quality: How consumers view stores and merchandise. Lexington, M.A.: Lexington Books.

Oliver, R. 1981. 'Measurement and evaluation of satisfaction processes in retail settings', Journal of Retailing, 57 (Fall):25-48.

Parasuraman, A., Zeithaml, V. A. \& Berry, L. L. 1988. 'SERVQUAL: A multiple-item scale for measuring consumer perceptions of service quality', Journal of Retailing, 64(1):12-40.

Peterson, R.A. 1994. 'A meta-analysis of Cronbach's coefficient alpha', Journal of Consumer Research, 27:381391.

Reichheld, F.F. \& Sasser, W.E. 1990. 'Zero defections: Quality comes to service', Harvard Business Review, 68 (September-October):105-111.

Sirohi, N., McLaughlin, E.W. \& Wittink, D.R. 1998. 'A model of consumer perceptions and store loyalty intentions for a supermarket retailer', Journal of Retailing, 74(2): 223245.

Steiger, J.H. \& Lind, J.C. 1990. Statistically based tests for the number of common factors. Paper presented at the annual meeting of the Psychometric Society, Iowa.

Westbrook, R.A. 1981. 'Sources of consumer satisfaction with retail outlets', Journal of Retailing, 57 (Fall):68-85.

Wu, B.T.W. \& Petroshuis, S.M. 1987. 'The halo effect in store image measurement', Journal of the Academy of Marketing Science, 15(3):44-51. 